\title{
State as an Institute of Research on the Personal Political Culture Determinant: Concept of Personal Political Culture, History, and Research
}

\author{
Lyazzat llimkhanova* \\ Corresponding Author, PhD, Independent Researcher, Member of Council For Innovative Research, \\ Email: lyazzat.ilimkhanova@gmail.com \\ Mukhan Perlenbetov
}

Doctor of Psychological Sciences; Professor and Vice-Rector of Kainar University; Academician of the Kazakh National Academy of Sciences, phd2014.kz@gmail.com

Mukhametkaliyeva Gulnar

Professor of the Department of Foreign Languages Kazakh National Technical University after Satpayev, Honoured Professor of International Management Institute of Canada

\section{Suranshiyeva Meiramgul Kadyrovna}

Senior Lecture of Chair of General, Age and Social Pedagogy KazNPU named after Abai

Mukanova Roza

Candidate of Chemical Sciences

Aliyasova Valentina

Candidate of Cultural Sciences

Asylbekova Gulmira

Candidate of Biological Sciences

Shaimardanova Botagoz

Candidate of Biological Sciences

Berikkhanova Aiman

\author{
Candidate of Pedagogical Sciences, Professor KazNPU after Abai, \\ Department of National Education and Self-Knowledge. Institute of Pedagogy and Psychology
}

Doi:10.5901/mjss.2015.v6n1s1p594

Abstract

Every nation, to one extent or another, has the right to its own opinion and promotion of its own vision of political ideals and value contents. In this context, it should not go without mention other countries' negative experiences on their way towards modernization and transition from the industrial to post-industrial structure. Emphasis should be placed on the fact that even the best examples of disregarding the state national characteristics will not be accepted by the society, resulting in hostile attitude growth. Such changes are dangerous enough for Russia as a multinational state. Wrong interpretations of the methods to improve the population quality of life might lead to interethnic or inter-religious hostility, discrediting the democracy concept itself and inciting regress in the country development process. According to many researchers' opinions, the contemporary government is one of the most important research institutes of political culture determinants. Government appears as a result of the nation long-lasting historical development, its changes representing effective factors hindering or accelerating certain 
individual political culture patterns emergence. Nevertheless, a detailed overview of the respective issues requires studying the entry of the "political culture" concept, the interaction of this phenomenon's determinants, and becoming aware of the significance of government as an institute of research on the political culture elements and transformations in terms of the societal impact and attitude.

Keywords: Modern state, social environment, determinants, political culture, relationship, institute, ethnic group, individual behavior, value systems

\section{Introduction}

Political culture and its research principles

Political science study, just as the study of most other scientific analytical works, requires more efforts to be made by researchers. To find causative basis and roots, it is necessary to go beyond the politics framework. To settle the basis, it is necessary to study the economy, the society's social structure, and of course culture. The concept of "political culture" emerged at the interface of culture and politics. As a research object, it yielded a new trend in the political science and allowed to evaluate the importance of external factors changes from another standpoint, these factors exerting impact on the basis and development of different societies, ethnic groups, communities, and individual behavior.

In most cases, this phenomenon is regarded in the context of political psychology, whereas the political culture becomes the main key to the separate individual conscience and the whole society's behavior. In particular, this research became a step forward for the Russian political science analysis because of most political institutes' imperfection, and it played a key role in terms of cultural identity for the society and Russian state development. In the 1980s, the interest in studying the political culture, as an important instrument for the extension of knowledge in politology, decreased. Research continued only in the 1990s, after the transition period; a lot of matters have been raised, the settlement of which required changing the research principle of the question, phenomena, impact factors, and consequences faced by the society within this period, as well as regarding the state as being the institute of research on the personal political culture determinants.

State Research and approaches of defining the state institute transformations. State impact and power system modernization on the individual political culture development.

Modern state - Key social institute subject to qualitative historical changes under the existing conditions; these changes resulting from the social and political disputes national development trends, as well as by the increasing state involvement in the flow of changes emerged on a global basis. These changes refer to a large parameters' spectrum and separate characteristics of this institute (attitudes of important actors, structural elements, internal and external correlation principles, basic functions, legalization mechanisms, and many others), but they also lead to another understanding of the government concept viewed in different dimensions. Such changes and processes require relevant methodological tools to be applied, thus ensuring an accurate evaluation at all scales of the modernization factors impact on political attitudes and society political culture.

The state is viewed by many researchers as the central integrative subject of politics, historically evolved as an institute ensuring (by symbolic and physical instruments) peaceful co-existence of humanity in one territory, being aimed at permanent reproduction of the social environment as an integral, system-related unit. Besides, one of the essential conditions for an effective development and real crystallization of state as an institute is the setting up of an organizational image, characterized by an internal heterogeneity from the functional and territorial viewpoints.

In other words, the state is a system, the basis of its functioning being aimed at the achievement of a certain goal. On the other hand, it is a union comprising multiple structures and actors bearing an autonomous and heterogeneouscharacter with regard to one vector, forming an environment that would be open for prospective individual development vectors and spontaneous consequences - that is, an environment that would be regulated to a greater extent by communicatory directives rather than the normative ones.

A similar practice is often supported by the institutional organization and changes in the authoritative and administrative staff machinery structure, provided there is no consecutivity of the emergence phenomenon. It is based on certain functional structures' operation and control; these structures perform not only diversified "sectorial" tasks, but are also characterized by their own, not necessarily planned, decision-generation patterns with a diversified political or regulatory impact on the society and political culture, in particular.

In the context of the social environment, this heterogeneity provides the required permanent competition-level for statutes and resources, including one significant statute - being a person representing the state as a whole at public areas level. 
Also, it should be emphasized that territorial and functional diffusion within one state as a consolidated institute generate conditions requires a permanent control of the internal unity sustenance. This necessity is based on the setting up of multiple policy-makers, including oppositional ones, around the official decisional Centre. These multiple structures take part directly in decision-making and the political culture multi-polarity setting up, taking into account the leading authorities influence spectrum and the existing control levers.

Nevertheless, evolution of such regulatory relations requires organization measures to be taken and assumes a stable existence of half-shade and shadowy interactions, thus supporting coordination of certain interests capable of disrupting the perception of the state as an institute acting in the limits of the public and political area only. It is possible that decision-making by government bodies would not be oriented at public announcement, for example, in the situations of the ruling groups' actions aimed at making decisions incompatible with the government-published goals.

Accent should be put on the connection of the government operation public aspect, assuming either partial or spontaneous structuring, as well as participation of the state bureaucracy, politicians, business structures, etc., and foreign counterparties in the decision-making process limited by the object and time-frames. The list of participants includes official and informal actors with no direct relation to the professional politics or state administration area. They express the public opinion and announce views on the situation within the state and outside of it, by addressing to the expert and political circles, as well as mass media. This connection refers to all state activity patterns in the context of public, shadowy, and half-shade areas; in case of interaction, this process turns into direct communication of state with its counterparties, exerting the necessary impact on the society value trends.

In the context of this political structure, dynamic characteristics of the state operation are set up, these characteristics going beyond the normative parameters and lying outside the contexts limiting the operational modeling and formalizing of processes referring to the state activity area.

The state organization is viewed as the key public institute and subject of the decision-making process to be considered multifunctional. Nevertheless, many qualitative transformations referring to the state basic parameters and characteristics, and corresponding to the modern society development context create new views on its conception definition.

\section{Research and Results}

State and reforms on its development as an important element at the individual political culture transformation stage The individual political culture is set up to proceed from multiple factors of influence, particularly reforms referring to the state modernization. Thus, an example may be not only Russia, but also countries that are not so large. In this case, there may be emphasized the North Caucasian nations (the Adygeis, the Kabardians and others). The political culture, values, principles of these ethnic groups have been subject to a strong influence as a result of the "old" social and political system collapse and shift to the soviet revolutionary transformations and socialism building. The watershed period affected many aspects of the social, cultural, political and economic life, the Caucasian nations being forced to implement new strategies of the subsistence areas adjustment. The political culture and values evolution depended on the conservatism and liability level, rigidity and adaptability of the Eastern culture to transformations, which became unavoidable after the events of 1917.

General collectivization of the beginning of the 30s of the XXth century forced the North Caucasian villages to face a new reality based on the unprecedented "attack" of the state on people, particularly on the productive part - peasantry. Changes were unavoidable and many nations sacrificed most of their values for the society benefit, this resulting in a new platform for abnormal transformations in the political culture of these ethnic groups.Also, a special emphasis shall be put on demographic changes of this period in many parts of RSFSR. Specific examples revealed data distortion cases neglected by the leading authorities. 


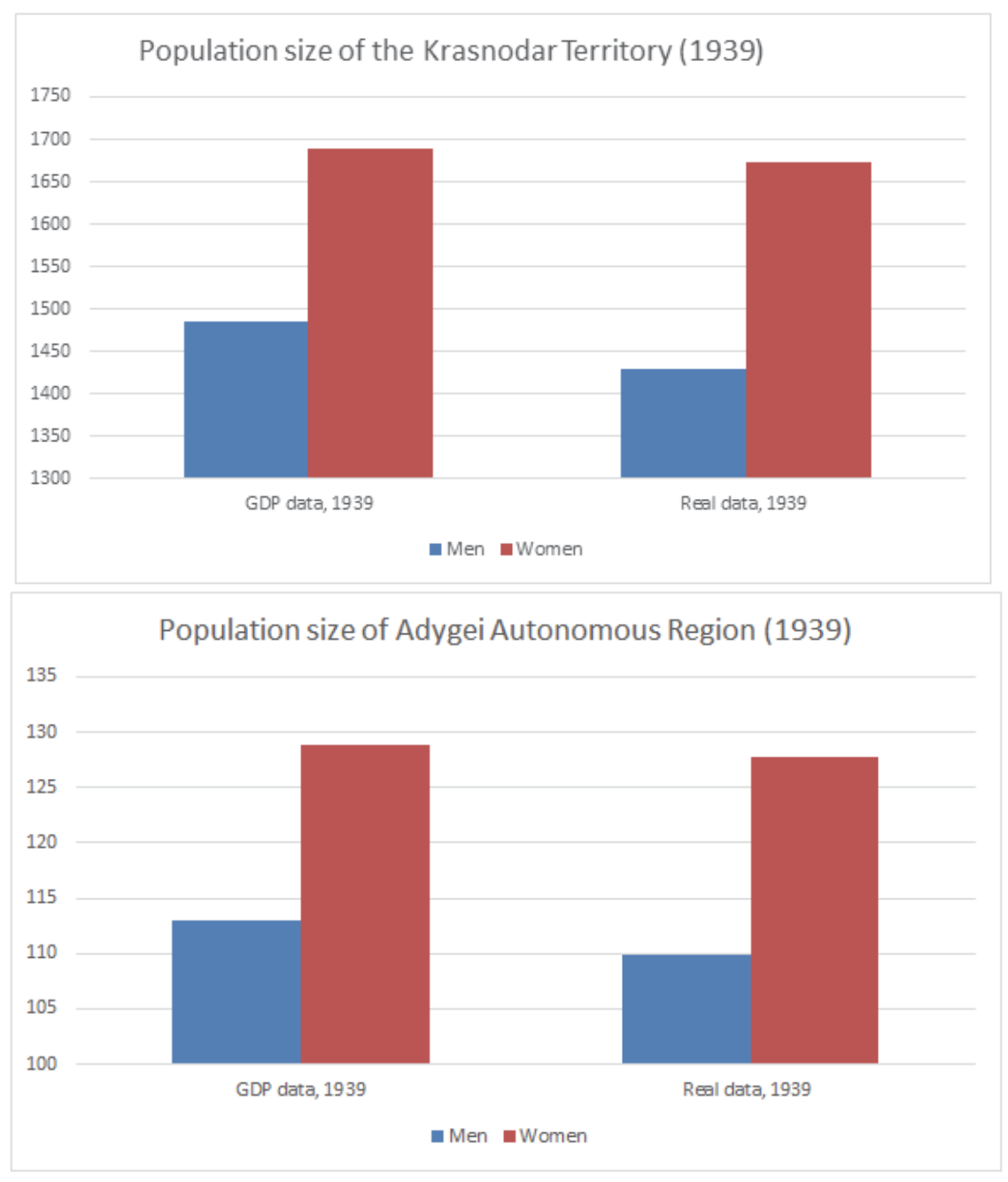

Recommend adding figure numbers and titles

During the North Caucasus collectivization period, the birth rate index was subject to changes. It was influenced by stringent abortion interdiction measures and struggles with evasion of alimony payments.

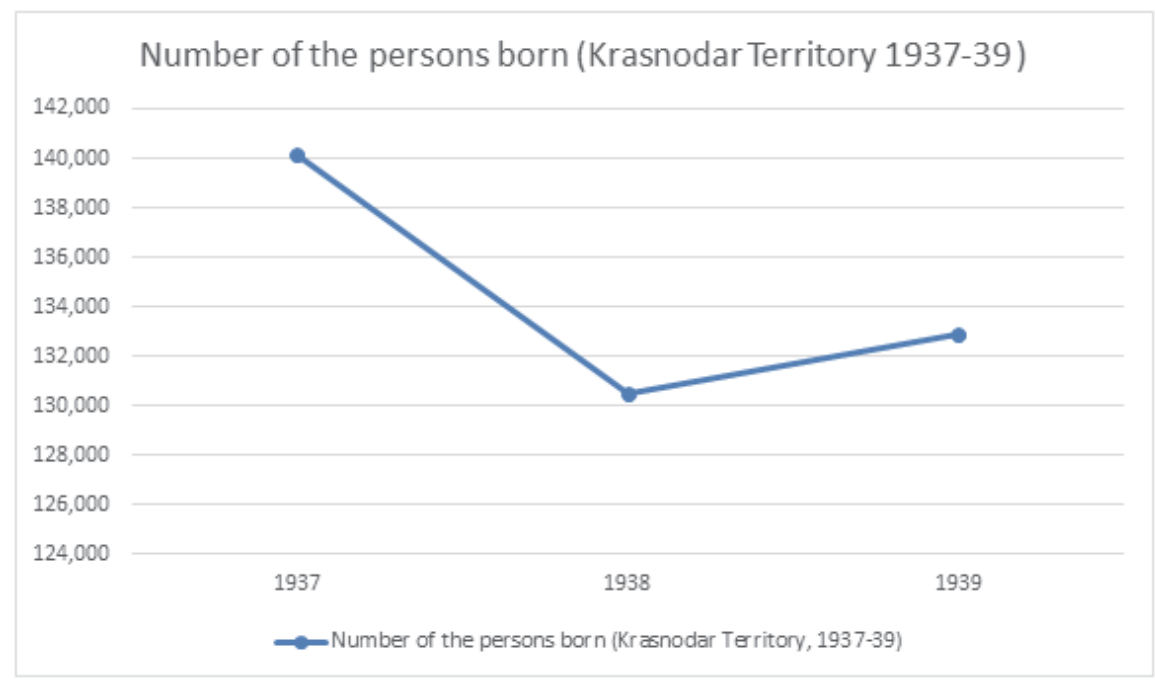


The second half of the 20th century is characterized by the ICT (information and communication technologies) development and expansion, this stage being an indicator of the new scientific and technological progress era. This fact was repeatedly emphasized by many authors involved in studying the digital information technology phenomenon of the 1970s. Qualitative transformations of the social and political area became the most important characteristic of this stage and had a direct connection with the information and communication processes and technical facilities development. With regard to the last decades' period, this factor should be considered one of the most significant ones in terms of transition of states from the industrial society model to the model of the information-oriented (post-industrial) society.

Society and political culture transformations in terms of the state post-industrial development trend affect not only the institutional organization of the state and society, but also, in particular, the relationship between them. At present, the individual political culture is set up in the context of the information-type interaction centers' relationship development. This resulted in a new organization form called mediacracy. It is based on the occasionally established communication between mass political subject and state, emphasizing significant projects.

Another important set of issues referring to changes in the state contemporary institute and reflected in the individual political culture emergence is its role in the international relations system and the global world. Investigations of D.Held and his co-authors show that the contemporary state management and policy go beyond the national frontiers, this making the delimiting process more complex - that is, the internal from the external spheres, the interstate from the intrastate matters. New interaction frameworks open the extraterritorial transformations of the political area, more adapted to the informational globalization, society political culture modernization, and interstate contacts expansion.This, in its turn, leads to the increase of the political power sources and the state sovereignty decentralization. In this context, on the one hand, there is a transmission of separate authority powers' traditional characteristics. On the other hand, there is an increase in each state's responsibility for the decisions adopted. This results from the growing response to local changes, yielding unpredictable transformations in the political culture and society behavior areas at the international level.

Research on the individual political culture and theoretical approaches. Transformations of state as an object of the individual political culture determinants analysis.

Theoretical search may not be considered as the dominating factor of interest in political culture. Investigations continued with gathering intensity as a result of political problems occurred in the course of the 20th century.

The main interest in political culture results from the state transformations. These processes may be conditionally divided into three periods:

- 1920-1930 - tendency to achieve social stability;

- 1960 s - necessity of political reform implementation as a result of the social restructuring;

- 1980still the beginning of the 90s - "velvet revolutions" in Central and Eastern Europe and the USSR collapse.

At the first stage, the researchers made efforts to find any possible ways to prevent social cataclysms and achieve the society peaceful and stable development. Proceeding from the deviations in the political system, no positive results could be achieved. For this reason, research of the sociologic and political aspects of the society behavior has been taken as a basis. Ch. Merriam (scientist, USA) was one of the first to choose this research method. Having performed a series of comparative analyses and studies in socialization and political culture in diverse societies and countries, he brought out a general title to works dating back to the 1928-1938 period - "Evolvement of Citizens.."

The second wave period refers to interest in political culture in terms of the decolonization processes intensification and increasing democratic attitudes in the Third World countries in the 1950-60s. In this period, the issue had many similarities with the democratization matter in most post-Soviet countries. Particularly, this refers to the consolidation of modernization processes and establishment of a good basis for stable political processes evolvement. Political culture becomes the most popular analysis tool.

\section{Discussion}

Interaction between state and political culture modernization within the contemporary society

Implementation of democracy in Eastern European countries and the majority of ex-socialist republics was based on the work principles of political institutes from Western countries. However, this course yielded contradictory results determined by the difference in cultures, and the unique pattern of attitudes and values characteristic of various ethnic groups. In this regard, significant processes have been noted within states; these processes go beyond the institutional frameworks and new political structures have been set up. This requires a new understanding of the democracy nature in developed industrial countries.

This period is characterized by a special attention to the culture issue in the context of the ruling regime, as well as the role of cultural modifications in the process of political changes. A deep study of the political culture marked the 
beginning of a new understanding of the lifestyle phenomenon, being very important for the society values emergence. The researcher A.Vildavski made a great contribution to the political culture study, emphasizing certain lifestyles based on values and social relations; however, despite this progress, by the mid-90s, the political culture concept was subject to criticism because of an insufficient productivity of the analysis of changes in countries subject to democratization. In particular, the leading German political expert, Max Kaaze, stated that considering the individual political culture as a basis for the research on state is as useless as trying to nail a spreading jelly to a wall. The metaphor found a response among researchers and it went on this way till the publication of successful works of R.Inglehart and R.Putnam. These scientists applied the political culture concept for narrower studies based on the examination of a certain national political culture, this study turning out to be a successful one. Additionally, the work of R.Dalton was distinguished. The book "Political science: new trends" obviously reflects effectiveness of the research on state and impact of the political culture development rate on the society; it also shows the significance of a "soft" non-institutional analysis, including the political institutes overview.

Interrelation between state and political culture in scientific literature

Systematic use of the "political culture" term became characteristic of the 1950s. This concept is applied by political experts to mark culture, ambience, values' set with an impact on the policy of the nation, ruling elite, state. In this context, it ranks together with the "frame of mind" term by Aristotle, "habit sweetness" by E.Berke, generating either revolution or stability, becoming the engine for the political institutes' progress. These terms may also be compared with the concepts of "feelings" and "values" reflected in the works of W. Bagehot, A. Dissey, and A. Tocqueville to explain the political progress trends. Up until now, the anthropologists and historians regard the state as being an accumulator of traditions and national character, becoming the political events defining factors. At present, it may certainly be stated that the most exact earlier prototype of "political culture" was the national character, as it was taken as a basis for the national peculiarities study, allowing performing a detailed research on differences in traditions, cultural patterns, and behavior with an impact on the political equilibrium in different nations' lives.

An important factor in the individual political culture basic values development is the state development vector and the political activity within the country, based on national priorities. The research of American psychologists performed at the end of the Second World War became an eloquent proof of this assertion. The "enemies,", namely the Japanese and the Germans, became the test objects. By that time, the main task of researchers was the search for any possible connections among the national psychology peculiarities; in this case, authoritarianism and the increasing popularization of the fascism trend. In this period, a commission was set up with a view to perform research on Germany "denazification.." The group consisted of the leading American and English scientists. The purpose of their activity was the formulation of recommendations on the selection of the most suitable candidates for the new German leadership posts.

During the "cold war" period, the Russian state was in the full glare of scientists; this particularly referred to the "Russian character" emergence, and namely the Bolshevism phenomenon occurred in the context of the Russian political culture development and the values' system setting up within a multinational society. Regarding this research trend, the works of N.Leytes, J. Dix, and G.Gorer became prominent. Despite this radical movement and the commitment of many Russian people to its progress, the authors characterized the national character of the Russians as being inclined to obedience and subordination to the ruling elite. Referring to the elite itself, the research workers, particularly J. Dix, concluded that this layer of society may not be considered as Russian by origin. This social class characteristic of the pre-revolutionary Russia has been under the foreign influence for a long time-period and it was distinguished by a pronounced ability to control its emotions and a strong will.

Peculiarities of the political mentality stirred a keen interest among the public representatives, being also subject to disputes at many state institutes' level. The book of $\mathrm{N}$. Leytes based on the study of the society political culture within the communist countries, with the description of the "national character" peculiarities and the political culture problems, was passed out to the American diplomatic officials during the Vietnamese and Korean wars. This trend has quickly found response among critics, who have distinguished the range of the studies' moral imperfections, particularly as a result of ignorance of the politics area (works of S. Verb), insufficiency of realism (works of S. White), and insufficient study of the national character issue (analysis of L. Pay).

By the beginning of the 1960s, the insufficiency of research activity on the national character issue became obvious. Researchers lacked new instruments to explain the political processes, which would allow developing the essence of the modernization patterns successful implementation and manifestation of the political forms of certain countries in the reality of others. There appeared the necessity to adopt the state itself as an institute of research on the individual political culture determinants. Further study of the issue was based on the works and conceptual views of American political experts (S. Verb. L. Pay, G. Almond, R. Tacker, S. Lipset) referring to the political culture as a values 
set. In this context, a certain political system was set up on the basis of a historical and psychological background, determining the evolvement of political events. Thus, the final result of works dating back to the 60 s was the conclusion on the compulsory conformity of the democracy political institutes to the political culture of the respective nation. In addition, revealing the values and norms characteristic of each specific culture and able to become independent variables in the period of state and state authorities transformation became a step towards the issue settlement.

Role of the state as an institute influencing the political interests and community political culture emergence

The importance of state for the political culture modernization is incontestable, as it may become both an accelerator and a neutralizer of changes in the life of a certain social category. The research shall start from defining the priority level of the respective institute in the cultural environment of the country. The selection shall be made proceeding from the dominant role or the marginal significance. Referring to Russia and post-Soviet space countries, it may be concluded that the political culture of these states was exclusively a "centric" one. Consequently, on the one hand, the state concentrates the power in terms of the society life, including even little things. The case of leaving abroad may be taken as an eloquent example. In the closing stages of his life, A.S. Pushkin tried to get the permission of the tsar to leave abroad. The tsar gave consideration to the poet's petition personally, but the result was a decisive refusal. Namely this pattern of limited freedom was applied further on in the Soviet system, wherein permissions on the people of art departure abroad were considered by the "higher-ups.." The French, Italian, and British people cannot adopt indifferently this political culture peculiarity of the Soviet people. By that time, many European countries eased the national passports regime, while the question of leaving abroad was settled at the local police station level.

On the other hand, it should be admitted that the result of this influence was the citizens' pronounced desire that the state makes decisions and takes the responsibility for the nation life and prosperity. The results of the investigations of the "Public Opinion" Fund may be considered as a confirmation. The inquiry held showed that $75 \%$ of the participants consider the state support as being a necessity, while $21 \%$ only expressed another opinion.

\section{Summary and Conclusions}

Methods of the state analysis as an institute of research on the political culture determinants and possible ways of the society topical problems settlement

The modern state institute keeps a range of ontological characteristics, but it also has new features resulting from the source of authority emergence and consolidation. Besides, emphasis should be put on the developing vertical and horizontal channel structures referring to powers of managerial authority transfer. In this regard, the political culture, particularly modern patterns implementation and their effective appliance, depend on the development of each separate state communication skills.

At present, the network methodology is one of the most effective sources of transformations generated by the Post-Modernism era and changing both the internal and external characteristics of the state institute. This approach allows carrying out a cognitive search of solutions to problems referring to the present-day effective development of the state institute. In other words, this approach allows distinguishing a new paradigm for the structural complexity of the contemporary world and state as an institute generating significant political culture determinants. The concept itself associated with political networks is a result of the mental abstraction represented by relevant studies based on empirical experience.

\section{Acknowledgements}

The work was based on the study of reports and writings of the leading specialists in the politology and psychology areas, namely: Cotenco V.I. (discourse: "Basic theoretical state-legal matters on the Russian political culture emergence and evolvement,," Ecaterinburg 2008), Shestopal E.B. (the work "Political psychology" studied). The works of Lavrinenko V.N. (study of the "Politology" coursebook, Moscow; 2002), Anchababidze I. based on the Middle East states and cultures transformations analysis, Kastels M. (referring to the influence of the Western reforms wave on the Russian society) have been subject to study. Also, the writings of the European and American scientific researchers have been examined.

\section{References}

Almond G., Verba S. ("Civic culture and democracy stability" // Polis.1992. No. 4);

Vasyutenkovl. V. ("Social health of the individual within the poly-cultural educational environment" // 2008);

VyatrE. ("Sociology of political relations" - M., 1979); 
GadjievK.S. («Political science: Teaching guide»-M., 1995);

GudimenkoD.V. ("Political culture in Russia: continuity of ages," Polis, 1994. No. 2);

Keyzerov N.M. ("On the correlation between the civic and political cultures. Sociologic and political sciences," 1991, No.7);

KrasilishikovV.A. (Round-table conference"Globalizationanddemocratization," Moscow, 1997);

PivovarovI.S. ("Political culture: Methodological study ISI RAS" - M., 1996);

PikalovG.A. ("Political culture. Teaching guide" - St. Petersburg, 2001);

SmorgunovL.V. ("Network-based methodology of research on politics" // Political analysis: Reports of the Empiric and Political Studies St. Petersburg State University. St. Petersburg, 2001)

ShulindinB.P. ("Historical way of Russia in the context of the civilizational and formational approaches"//Humanities and social knowledge No. 2 2001);

RakacevV.N. ("Demographic consequences of the collectivism policy in North Caucasus and data distortion").

All-Union Population Census, 1939. Major Results. M., 1940, JiromskayaV.B. 